\title{
Reduced Kiss-1 expression is associated with clinical aggressive feature of gastric cancer patients and promotes migration and invasion in gastric cancer cells
}

\author{
CHAO LI $^{1 *}$, LI YUAN $^{2 *}$, SHUANGSHUANG HAN $^{1}$, MINGDA XUAN $^{1}$, DEHUA LIU $^{1}$, BO TIAN ${ }^{1}$ and WEIFANG YU ${ }^{1}$ \\ ${ }^{1}$ Department of Endoscopy Center, The First Hospital of Hebei Medical University, Shijiazhuang, Hebei 050031; \\ ${ }^{2}$ Department of Endoscopy Center, The Fourth Hospital of Hebei Medical University, Shijiazhuang, Hebei 050011, P.R. China
}

Received January 23, 2020; Accepted June 10, 2020

DOI: $10.3892 /$ or.2020.7676

\begin{abstract}
Gastric cancer (GC) causes high morbidity and mortality in patients largely due to its invasion and metastasis. Kiss -1 has been shown to be a metastasis suppressor in various malignancies. However, its clinical significance and biological functions in GC have not been thoroughly investigated. The present study investigated the association between Kiss-1 expression and its methylation status and clinicopathological features in GC. Kiss-1 expression was reduced in GC and its low expression was associated with poor histological grade, lymph node metastasis and TNM III+IV stage. Kiss- 1 overexpression in AGS GC cells significantly inhibited cell proliferation, migration and invasion in vitro. Kiss- 1 knockdown promoted the proliferation, migration and invasion of HGC-27 cells. In summary, the data demonstrated that a low expression of Kiss- 1 played a suppressive role for the proliferation, migration and invasion of GC cells. Its expression and methylation levels were associated with the clinical progression of GC. Thus, Kiss- 1 is a potential diagnostic and prognostic marker as well as a new target for the treatment of GC.
\end{abstract}

\section{Introduction}

Gastric cancer (GC) is one of the most common malignant tumors in the digestive system. According to the latest statistics of GLOBOCAN, there were approximately 1,033,000 new cases of GC worldwide in 2018, with approximately 783,000 fatalities (1). Based on this evidence, GC ranks 5th in the incidence of malignant tumors and 2nd in mortality worldwide (1)

Correspondence to: Dr Weifang Yu, Department of Endoscopy Center, The First Hospital of Hebei Medical University, 89 Donggang Road, Shijiazhuang, Hebei 050031, P.R. China

E-mail: ydyynjzx@126.com

${ }^{*}$ Contributed equally

Key words: Kiss-1, gastric cancer, metastasis suppressor gene, clinical progress, proliferation, migration, invasion
Although various comprehensive treatments including surgical resection, radiotherapy and chemotherapy have been used at different stages of the disease, the incidence, mortality and impaired quality of life thereof are on the increase (2). Therefore, it is necessary to explore new biomarkers and therapeutic targets that may aid the development of targeted therapies for GC.

Metastasis suppressor genes play a key role in tumor metastasis. A previous study demonstrated that the effects of metastasis suppressor genes on tumor metastasis were more critical than those of metastasis promoter genes and that the reduction in the expression levels of metastasis suppressor genes or their loss of expression may induce the invasion and metastasis of tumor cells (3). Kiss-1 was initially identified as an important tumor metastasis suppressor gene in human melanoma cells (4). Kiss-1 is located on the long arm of human chromosome-1. The protein-encoding gene acts as an endogenous ligand for G-protein coupled receptor 54 and produces a variety of physiological effects, including inhibition of tumor cell proliferation, metastasis, invasion and induction of tumor cell differentiation and apoptosis $(5,6)$. A decrease in Kiss- 1 levels and the role of this protein in tumor invasion and metastasis have been evaluated in various tumors, such as those of the bladder (7), colorectum (8) and breast (9). However, the expression levels of Kiss- 1 and its pathogenesis in GC remain to be elucidated.

The present study examined the methylation status and expression levels of Kiss- 1 in GC tissues and subsequently assessed the association between Kiss-1 methylation, Kiss-1 expression and clinicopathological features. The effects of Kiss- 1 on the biological function of specific GC cell lines were also studied. The primary aim of the study was to investigate the role of Kiss-1 in the development and progression of GC and whether it could be used for the prevention or treatment of this disease. The data demonstrated that a low expression of Kiss-1 played a suppressive role for the proliferation, migration and invasion of GC cells, rendering Kiss- 1 a potential diagnostic and prognostic marker.

\section{Materials and methods}

Patients and specimens. Samples from GC and non-tumor tissues were collected at the time of surgical resection at the 
First Hospital of Hebei Medical University from June 2014 to June 2016. The samples were snap-frozen in liquid nitrogen and stored at $-80^{\circ} \mathrm{C}$. Paraffin-embedded tissues were prepared at the Department of Pathology at the same hospital. All diagnoses of GC and gastritis were confirmed by histopathological examination. The relevant information regarding patient history and disease characteristics was extracted from a review of the patients' medical records. The present study was approved by the Institutional Ethical Review Committee of the First Hospital of Hebei Medical University and adhered to the principles of the Declaration of Helsinki. Informed consent was obtained from each patient prior to the collection of the tissues.

Cell culture. Human GC cells (AGS and HGC-27) were purchased from the Culture Collection of the Chinese Academy of Sciences and cultured in F-12k (AGS) and RPMI-1640 (HGC-27) (Gibco; Thermo Fisher Scientific, Inc.) supplemented with $10 \%$ fetal bovine serum (FBS), $100 \mu / \mathrm{ml}$ penicillin and $50 \mathrm{mg} / \mathrm{ml}$ streptomycin. The cells were incubated at $37^{\circ} \mathrm{C}$ in a humidified atmosphere of $5 \% \mathrm{CO}_{2}$. The cells were authenticated by STR analysis and no cross-contamination from other cell lines was found.

Methylation analyses of the promoter of Kiss-1. The primers used were as follows: Methylated Kiss-1 forward, 5'-AAAGTT TCGTTTCGGAGGGTTC-3' and reverse, 5'-CTTTTATAA AACCCGAAATAACG-3', unmethylated Kiss-1 forward, 5'-AAAGTTTTTTTTGGGGGTTT-3' and reverse, 5'-CCT TTTATAAAACCCAAAATAACA-3' (10). The specific location of methylation sites in Kiss-1 promoter region is shown in Fig. 1A. Genomic DNA from GC patient tissue was extracted and modified with sulfite using Universal Genomic DNA Kit and DNA Methylation Kit (CWBIO, Inc.). Methylation-specific PCR (MSP) with GoldStar Master Mix (CWBIO, Inc.) was also employed according to the manufacturer's protocol. The thermocycling conditions were: Pre-denaturation at $95^{\circ} \mathrm{C}$ for $10 \mathrm{~min}$, denaturation at $95^{\circ} \mathrm{C}$ for $45 \mathrm{sec}$, annealing for $45 \mathrm{sec}$ (methylation-specific primer amplification annealing temperature $59^{\circ} \mathrm{C}$, non-methylation specific primer amplification annealing temperature $55^{\circ} \mathrm{C}$ ) and extension at $72^{\circ} \mathrm{C}$ for $50 \mathrm{sec}$. A total of 34 cycles were performed and the final extension was conducted at $72^{\circ} \mathrm{C}$ for $7 \mathrm{~min}$. The reaction products were separated by $2.0 \%$ agarose gel electrophoresis and detected with Ethidium Bromide staining. During electrophoresis, the methylated positive control (CpG methylation enzyme modification of DNA extracted from fresh placental tissues used as a template), the unmethylated positive control (DNA extracted from fresh placental tissues used as a template) and the negative control $\left(\mathrm{H}_{2} \mathrm{O}\right)$ were established. The data were collected using a UV transilluminator (Alpha Innotech Corporation; ProteinSimple) and subsequently analyzed by AlphaView 3.4 (Alpha Innotech Corporation; ProteinSimple).

RNA extraction and reverse transcription PCR (RT-qPCR). Total RNA was extracted from cell or from GC tissues using TRIzol ${ }^{\circledR}$ (Invitrogen; Thermo Fisher Scientific, Inc.) and cDNA was synthesized with the PrimeScript RT reagent kit (Takara Bio, Inc.) according to the manufacturer's instructions. Subsequently, Kiss-1 expression levels were quantified by RT-qPCR using the AceQ qPCR SYBR-Green Master Mix (Vazyme Biotech, Co. Ltd.) in an ABI-7500 quantitative PCR instrument. Gene expression was defined based on $\mathrm{Cq}$ values and the gene expression levels were normalized compared with those of the housekeeping gene $G A P D H$. The $2^{-\triangle \Delta \mathrm{Cq}}$ method (11) was used to calculate the relative changes in the expression levels. The thermal cycling conditions used were: $95^{\circ} \mathrm{C}$ for $5 \mathrm{~min}$, followed by 40 cycles at $95^{\circ} \mathrm{C}$ for $10 \mathrm{sec}, 60^{\circ} \mathrm{C}$ for $30 \mathrm{sec}$ and $95^{\circ} \mathrm{C}$ for $15 \mathrm{sec}, 60^{\circ} \mathrm{C}$ for $60 \mathrm{sec}$ and $95^{\circ} \mathrm{C}$ for $15 \mathrm{sec}$. The primers used for Kiss 1 were the following: Forward: 5'-CTC ACTGGTTTCTTGGCAGC-3'; reverse: 5'-CTGGCTTCCTCT CGGTGC-3'. GAPDH was used as an internal reference control and its detection was performed with the following primers: Forward: 5'-GAGTCAACGGATTTGGTCGT-3' and reverse: 5'-CATGGGTGGAATCATATTGGA-3'.

Detection of the expression levels of Kiss-1 protein by immunohistochemistry. The GC tissue was fixed in $10 \%$ neutral formalin for 24-48 $\mathrm{h}$ at room temperature and then cut into paraffin sections $(4 \mu \mathrm{m})$. The sections were placed into a $60-65^{\circ} \mathrm{C}$ box overnight and deparaffinized in green transparent agent, rehydrated with an alcohol gradient and washed briefly in distilled water. For antigen retrieval, the sections were boiled in $0.01 \mathrm{M}$ citrate buffer ( $\mathrm{pH} \mathrm{6.0)}$ for $20 \mathrm{~min}$ at $100^{\circ} \mathrm{C}$ and washed in PBS three times prior to cooling to room temperature. Endogenous peroxidase activity was blocked with $3 \% \mathrm{H}_{2} \mathrm{O}_{2}$ (Bohai) for $30 \mathrm{~min}$ and the sections were washed in PBS three times. Subsequently, the sections were incubated with normal sheep serum for $30 \mathrm{~min}$ at room temperature and at $4^{\circ} \mathrm{C}$ overnight with rat Anti-Kiss peptin monoclonal antibody (1:100 dilution; cat. no. ab55384; Abcam). The following day, the sections were rinsed with fresh PBS and incubated with biotinylated secondary antibody working solution and horseradish enzyme-labeled streptavidin (cat. no. SP-9002; ZSGB Biotech) working solution at room temperature for $30 \mathrm{~min}$. Finally, the sections were stained with 3,3'-diaminobenzidine (cat. no. ZLI-9032; ZSGB Biotech) for visualization. Five fields were randomly selected from the slices and scored according to the percentage of positive cells in the field. The scoring system was as follows: $<5 \%$ corresponded to $0,6-25 \%$ to $1,26-50 \%$ to 2 and $\geq 51 \%$ to 3 . The staining intensity score used was as follows: None corresponded to 0 , light yellow to 1 , yellow to 2 and brown to 3 . When the two aspects were added together, a score of $\leq 3$ indicated negative expression, while a score $>3$ positive expression.

Vectors and transfection of the target genes. Kiss-1 m98 and the control m98 vectors were transfected into AGS GC cells using Lipofectamine 2000 (Invitrogen; Thermo Fisher Scientific, Inc.). Kiss- 1 sh and NC sh were also transfected into HGC-27 GC cells. The transfection efficacy was evaluated by RT-qPCR and western blot analyses.

Western blot analysis. Total protein was extracted from cell using RIPA lysis buffer containing proteinase inhibitor (Solarbio Science \& Technology Co. Ltd.), and quantified using the bicinchoninic acid protein assay (Solarbio Science \& Technology Co. Ltd.) as recommended by the manufacturers. Approximately $20 \mu \mathrm{g}$ of total protein was separated by $10 \%$ SDS-PAGE and transferred to a polyvinylidene 
difluoride membrane (EMD Millipore). The membrane was blocked with $5 \%$ skimmed milk in PBS-T $(10 \mathrm{mmol} / 1$ Tris, $145 \mathrm{mmol} / \mathrm{NaCl}, \mathrm{pH}$ 7.2-7.4) for $2 \mathrm{~h}$ at room temperature and subsequently incubated with mouse monoclonal antibody against Kiss-1 (1:1,000 dilution; cat. no. ab55384; Abcam) or mouse monoclonal antibody against $\beta$-actin (1:3,500 dilution; cat. no. 60008-1-1 g; ProteinTech Group, Inc.) overnight at $4^{\circ} \mathrm{C}$. Anti-mouse IgG (1:2,500 dilution; cat. no. A23910; Abbkine Scientific Co. Ltd.) was used and the signal was developed with a chemiluminescent substrate. The images were obtained with an Odyssey CLX infrared fluorescence scanning imaging system (LICOR) and the intensity of the bands was analyzed using Image $\mathbf{J}$ software (National Institute of Health).

Cell proliferation assay. The transfected cells were independently seeded in 96-well plates and cultured for 24, 48, 72 or $96 \mathrm{~h}$. The Cell Counting Kit-8 (MedChemExpress) was added to each well and the cells were incubated at $37^{\circ} \mathrm{C}$ for $3 \mathrm{~h}$. Absorbance was measured at $450 \mathrm{~nm}$ using a microplate reader (Promega Corporation).

Transwell migration and Matrigel invasion assays. Cell migration and invasion were measured using $8 \mu \mathrm{m}$ Transwell chambers (Corning, Inc.). To measure migration, $3.5 \times 10^{4}$ transfected cells were resuspended in $300 \mu \mathrm{l}$ serum-free F-12K or RPMI-1640 medium and added to the upper chamber, whereas $800 \mu 1 \mathrm{~F}-12 \mathrm{~K}$ or RPMI-1640 medium containing $10 \%$ FBS was added to the lower chamber. To measure invasion, a chamber containing Matrigel (Corning, Inc.) was used and the assay was performed as stated before. Following $24 \mathrm{~h}$ of incubation, the chamber was stained by diff-quick staining and the cells were counted in five random fields under a light microscope with a magnification of $x 200$. The number of cells was expressed as an average.

Wound healing assay. When the transfected cells reached a growth density of $85 \%$, the confluent monolayers were scratched with a pipette tip in order to create a gap to simulate a wound and the non-viable cells were washed with PBS. The transfected cells were cultured in RPMI-1640. The images of the plates were obtained under a microscope (Olympus Corporation) at 0,24 and $48 \mathrm{~h}$.

Statistical analysis. All results are shown as mean \pm SD and were analyzed using GraphPad Prism 7 (GraphPad Software Inc.). The differences determined in the in vitro experiments were analyzed using the unpaired two-tailed t-test and the cellular experiments were repeated three times. The differences determined in the clinical tissue experiments were analyzed using the Pearson's Chi-square test. $\mathrm{P}<0.05$ indicated significant differences.

\section{Results}

Methylation-specific PCR (MSP) analysis of Kiss-1 gene promoter methylation. The MSP data indicated that hypermethylation of the Kiss-1 gene promoter was observed in $78.43 \%(40 / 51)$ of the GC tissues, whereas this process was present only in $53.49 \%(23 / 43)$ of the non-tumor tissues (Fig. 1B). Chi-square analysis of the patient data collected

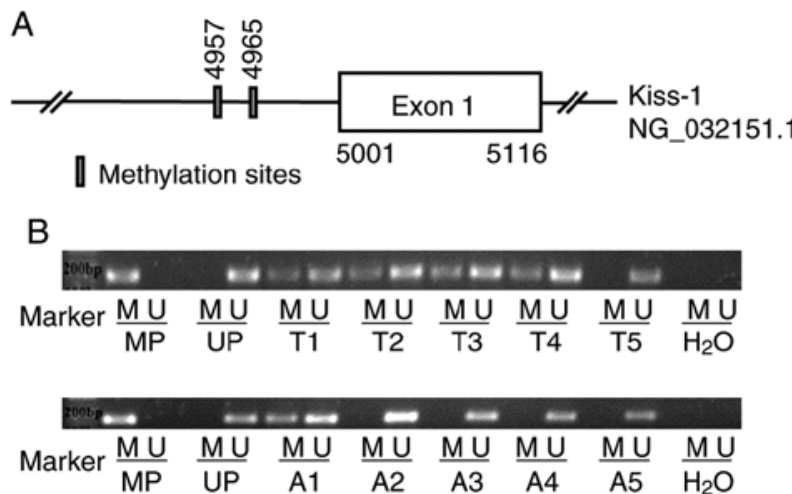

Figure 1. Promoter methylation of Kiss-1 in GC. (A) The specific location of methylation sites in Kiss-1 promoter region. (B) The methylation status of Kiss-1 in GC tissues and adjacent cancer tissues. M, methylation; U, unmethylation; T1 T5, gastric cancer tissues; A1-A5, adjacent gastric normal tissues; MP, Methylated positive contrast; UP, Unmethylated positive contrast; $\mathrm{H}_{2} \mathrm{O}$, blank contrast.

indicated that the hypermethylation of the Kiss-1 promoter in GC was significantly associated with TNM III+IV stage and lymph node metastasis $(\mathrm{P}<0.05)$. However, no significant correlation was noted between the Kiss-1 promoter hypermethylation and other clinicopathological variables such as age, sex and histological grade ( $\mathrm{P}>0.05$; Table I).

Kiss-1 mRNA and protein expression in GC. The mRNA expression levels of Kiss-1 were evaluated in 53 GC tissue samples and 53 non-tumor tissue samples. The data indicated that the levels of Kiss-1 in the GC tissues were significantly downregulated compared with those of the normal tissues (Fig. 2A). The expression levels of the Kiss-1 protein were assessed in 56 paired GC and adjacent non-tumor tissues by immunohistochemistry. The data demonstrated that Kiss-1 was expressed in the cytoplasm of gastric carcinoma cells (Fig. 2B). Kiss-1 staining was detected in $48.21 \%$ (27/56) of GC tissues and its positive expression was significantly lower in adjacent non-tumor tissues $82.14 \%$ (46/56). The correlation between Kiss- 1 expression and clinicopathological features was also analyzed in patients with GC. Low expression levels of Kiss-1 in GC tissues were significantly associated with poorly histological grade, lymph node metastasis and TNM III+IV stage $(\mathrm{P}<0.05)$. No significant association was observed with the remaining variables including age, sex, tumor size, or depth of invasion $(\mathrm{P}>0.05$; Table II).

Regulation of the Kiss-1 gene in GC cells. The AGS and HGC-27 cell lines were selected to investigate the biological function of Kiss-1 in GC. Transfection of Kiss-1 m98 vector into AGS cells resulted in a significant upregulation of the expression of Kiss-1 at both the mRNA and protein levels (Fig. 3A and B), whereas transfection of Kiss- 1 sh significantly downregulated the transcription and synthesis of Kiss-1 in HGC-27 cells (Fig. 3C and D).

Effects of Kiss-1 overexpression on migration, invasion and proliferation of AGS cells. The number of cells migrating through the chamber in Kiss-1 m98 was significantly lower than that noted in the $\mathrm{m} 98$ and control groups $(\mathrm{P}<0.05)$. 
Table I. Association between clinicopathological features and Kiss-1 methylation in 40 patients with GC.

Kiss-1 methylation

\begin{tabular}{|c|c|c|c|c|c|c|}
\hline Clinicopathological features & No. of patients & Positive & Negative & Positive rate (\%) & $\chi^{2}$ & P-value \\
\hline Adjacent tissues & 30 & 10 & 20 & 33.33 & 10.658 & $0.001^{\mathrm{a}}$ \\
\hline Gastric carcinoma & 40 & 29 & 11 & 72.50 & & \\
\hline \multicolumn{7}{|l|}{ Sex } \\
\hline Male & 32 & 24 & 8 & 75.00 & 0.071 & 0.791 \\
\hline Female & 8 & 5 & 3 & 62.50 & & \\
\hline \multicolumn{7}{|l|}{ Age (years) } \\
\hline$\leq 65$ & 18 & 15 & 3 & 83.33 & 1.065 & 0.302 \\
\hline$>65$ & 22 & 14 & 8 & 63.64 & & \\
\hline \multicolumn{7}{|l|}{ Histological grade } \\
\hline Poorly & 14 & 9 & 5 & 64.29 & 0.233 & 0.629 \\
\hline Well, Moderately & 26 & 20 & 6 & 76.92 & & \\
\hline \multicolumn{7}{|l|}{ Depth of infiltration } \\
\hline Soaked in serosa & 19 & 14 & 5 & 73.68 & 0.025 & 0.873 \\
\hline Not soaked in the film & 21 & 15 & 6 & 71.43 & & \\
\hline \multicolumn{7}{|l|}{ Lymph node metastasis } \\
\hline Presence & 24 & 21 & 3 & 87.50 & 5.021 & $0.025^{\mathrm{a}}$ \\
\hline Absence & 16 & 8 & 8 & 50.00 & & \\
\hline \multicolumn{7}{|l|}{ TNM stage } \\
\hline $\mathrm{I}+\mathrm{II}$ & 15 & 7 & 8 & 46.67 & 6.094 & $0.014^{\mathrm{a}}$ \\
\hline $\mathrm{III}+\mathrm{IV}$ & 25 & 22 & 3 & 88.00 & & \\
\hline
\end{tabular}

a Statistically significant result.

A

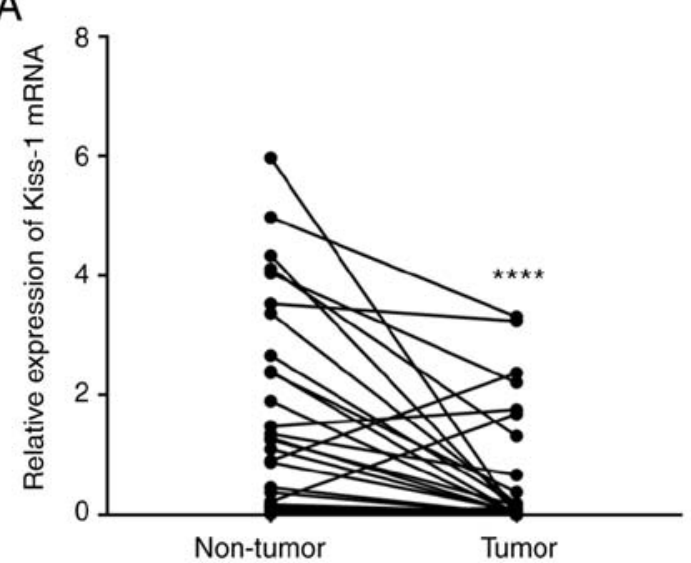

B
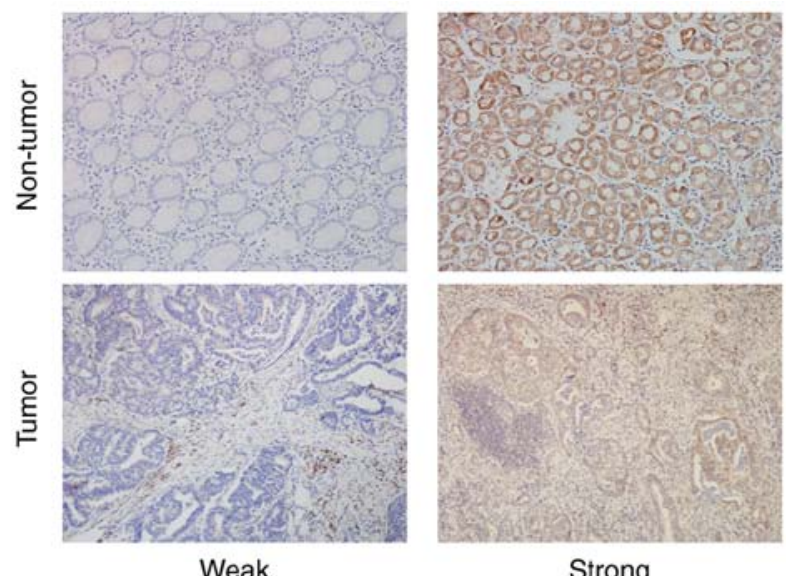

Strong

Figure 2. Expression level of Kiss-1 in GC. (A) Expression of Kiss-1 mRNA was deteced by qPCR in GC and non-tumor tissues; ${ }^{* * * *} \mathrm{P}<0.0001$. (B) Expression of Kiss-1 protein was detected with immunohistochemical staining in GC and non-tumor tissues. Original magnification: x200.

Similarly, the number of cells invading through the chamber in Kiss-1 m98 was significantly lower than that of the m98 and control groups $(\mathrm{P}<0.05)$ (Fig. 4A and B). The scratch healing rate of Kiss-1 m98-transfected cells was significantly lower than that of the $\mathrm{m} 98$ and control groups $(\mathrm{P}<0.05)$ (Fig. 4C and D). In addition, the cell OD values were significantly reduced at 48,72 and $96 \mathrm{~h}$ in the Kiss $-1 \mathrm{~m} 98$ group (Fig. 4E). The results indicated that overexpression of
Kiss-1 inhibited the migration, invasion and proliferation of GC cells.

Effects of Kiss-1 knockdown on migration, invasion and proliferation of HGC-27 cells. Transwell migration, matrigel invasion and wound healing assays were performed following transfection of HGC-27 cells with Kiss-1 sh in order to assess migration and invasion in GC cells devoid of Kiss-1. 
Table II. Relationship between expression of Kiss-1 and clinicopathological variables in 56 patients with GC.

\begin{tabular}{|c|c|c|c|c|c|c|}
\hline \multirow[b]{2}{*}{ Clinicopathological features } & \multirow[b]{2}{*}{ No. of patients } & \multicolumn{2}{|c|}{ Kiss- 1 staining } & \multirow[b]{2}{*}{ Expression rate $(\%)$} & \multirow[b]{2}{*}{$\chi^{2}$} & \multirow[b]{2}{*}{ P-value } \\
\hline & & Strong & Weak & & & \\
\hline Adjacent tissues & 56 & 46 & 10 & 82.14 & 14.202 & $<0.001^{\mathrm{a}}$ \\
\hline Gastric carcinoma & 56 & 27 & 29 & 48.21 & & \\
\hline \multicolumn{7}{|l|}{ Sex } \\
\hline Male & 38 & 20 & 18 & 52.63 & 0.924 & 0.336 \\
\hline Female & 18 & 7 & 11 & 38.89 & & \\
\hline \multicolumn{7}{|l|}{ Age (years) } \\
\hline$\leq 62$ & 28 & 13 & 15 & 46.43 & 0.072 & 0.789 \\
\hline$>62$ & 28 & 14 & 14 & 50.00 & & \\
\hline \multicolumn{7}{|l|}{ Tumor size $(\mathrm{cm})$} \\
\hline$\leq 4$ & 36 & 19 & 17 & 52.78 & 0.841 & 0.359 \\
\hline$>4$ & 20 & 8 & 12 & 40.00 & & \\
\hline \multicolumn{7}{|l|}{ Histological grade } \\
\hline Poorly & 23 & 7 & 16 & 30.43 & 4.941 & $0.026^{\mathrm{a}}$ \\
\hline Well, Moderately & 33 & 20 & 13 & 60.61 & & \\
\hline \multicolumn{7}{|l|}{ Depth of infiltration } \\
\hline Soaked in serosa & 35 & 13 & 22 & 37.14 & 4.582 & 0.032 \\
\hline Not soaked in the film & 21 & 14 & 7 & 66.67 & & \\
\hline \multicolumn{7}{|l|}{ Lymph node metastasis } \\
\hline Presence & 32 & 8 & 24 & 25.00 & 16.116 & $<0.001^{\mathrm{a}}$ \\
\hline Absence & 24 & 19 & 5 & 79.17 & & \\
\hline \multicolumn{7}{|l|}{ TNM stage } \\
\hline $\mathrm{I}+\mathrm{II}$ & 31 & 23 & 8 & 74.19 & 18.771 & $<0.001^{\mathrm{a}}$ \\
\hline III+IV & 25 & 4 & 21 & 16.00 & & \\
\hline
\end{tabular}

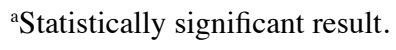

The number of cells migrating through the chamber in Kiss- 1 sh cells was significantly higher than that in the NC sh and control groups (Fig. 5, $\mathrm{P}<0.05$ ). Similarly, the number of cells invading through the chamber in the Kiss- 1 sh group was significantly higher than that noted in the NC sh and control groups $(\mathrm{P}<0.05)$. The scratch healing ability of Kiss-1 sh-transfected HGC-27 cells was significantly higher than that of the $\mathrm{NC}$ sh and control groups $(\mathrm{P}<0.05)$. In addition, the OD values were significantly increased at 48,72 , and $96 \mathrm{~h}$ in the sh group (Fig. 5E). It was deduced that knockdown of Kiss-1 enhanced cell migration, invasion and proliferation.

\section{Discussion}

GC is the fifth most common cancer in the world and the second most lethal cancer (1). The vast majority of GC fatalities are caused by complications caused by tumor cell metastasis. The signaling pathways involved in the initial control of the tumor cells are activated and the primary tumor cells migrate into adjacent tissues (12). Following contact of the tumor cells with blood and lymphatic vessels, the basement membrane and the endothelial wall are penetrated and the cells are dispersed through the lumen of blood vessels to reach distant organs, facilitating the progression of metastasis $(13,14)$. Therefore, investigation of the expression of tumor metastasis suppressor genes that interfere with specific points in these steps and block the metastatic cascade is critical for early diagnosis, treatment and improved clinical outcomes of GC patients. The Kiss-1 gene was initially reported as a novel metastasis suppressor gene in human melanoma and breast cancer cells $(15,16)$. The translation product of Kiss -1 is a protein containing 145 amino acids, which is further cleaved into Kisspeptin-10, -13, -14 and -54 proteins $(17,18)$. Kiss- 1 proteins bind specifically to GPR54 (AXOR12 or hOT7T175) and induce the release of the secondary messenger inositol trisphosphate (IP3) and of the diglycerides, which play a role in cell proliferation, differentiation and apoptosis $(5,6)$.

However, the expression levels of Kiss -1 and its pathogenesis in $\mathrm{GC}$ remain unclear. To investigate the mechanism of action of Kiss- 1 in GC, the association of promoter methylation with the clinicopathological data was investigated with regard to GC progression. In the present study, hypermethylation of Kiss-1 was present in GC tissues compared with the corresponding levels noted in adjacent tissues, indicating that methylation of Kiss-1 may contribute to the progression of GC. Statistical analysis of the levels of the Kiss-1 promoter methylation and 
A
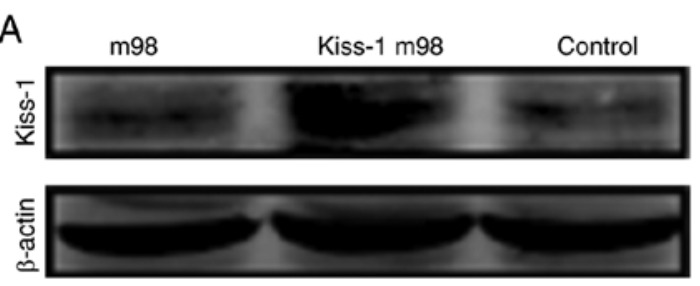

$\mathrm{C}$
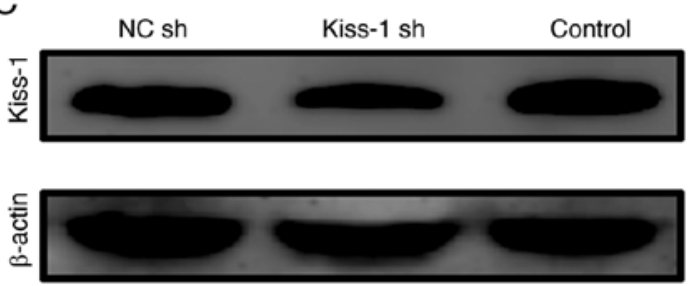

B

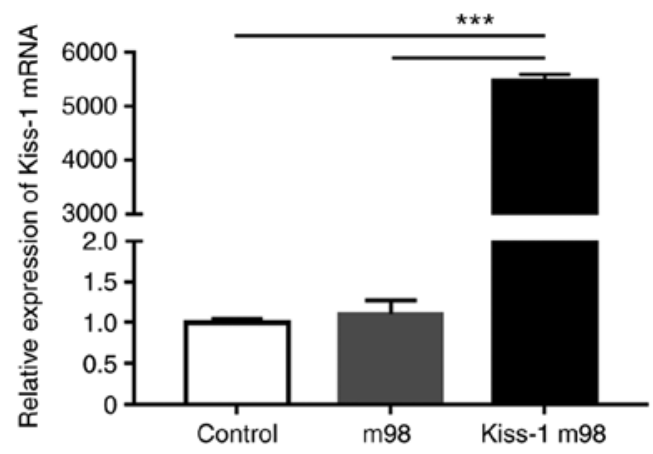

D

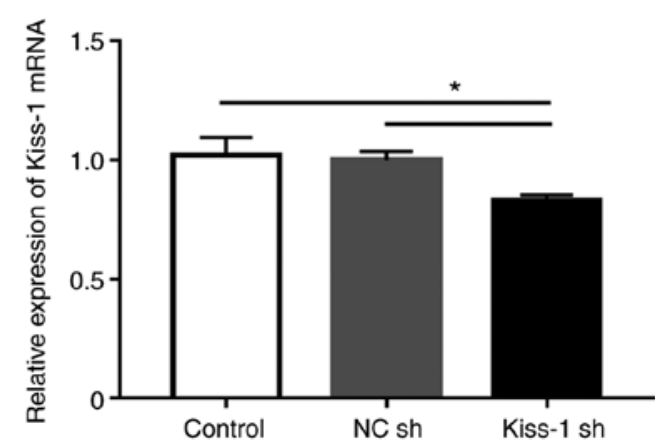

Figure 3. Expression of Kiss-1 mRNA and protein in AGS and HGC-27 cells after transfection. (A and B) Western blot and qPCR analyses after Kiss-1 m98 vector transfection in AGS. (C and D) Western blot and qPCR analyses after Kiss-1 sh transfection in HGC-27. Significantly different from m98 and control group $\left({ }^{* * *} \mathrm{P}<0.001\right)$, and $\mathrm{NC}$ sh and control group $\left({ }^{*} \mathrm{P}<0.05\right)$.

A
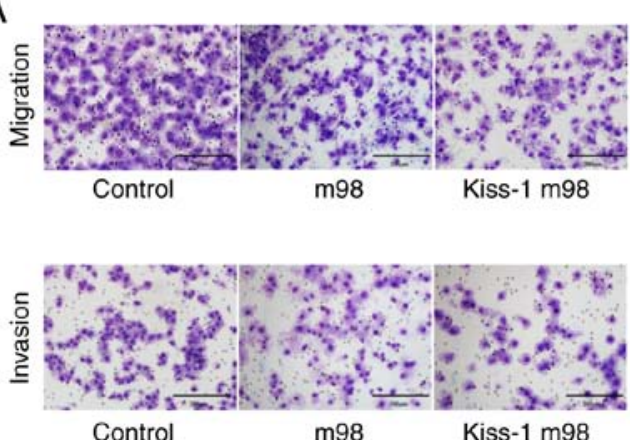

C

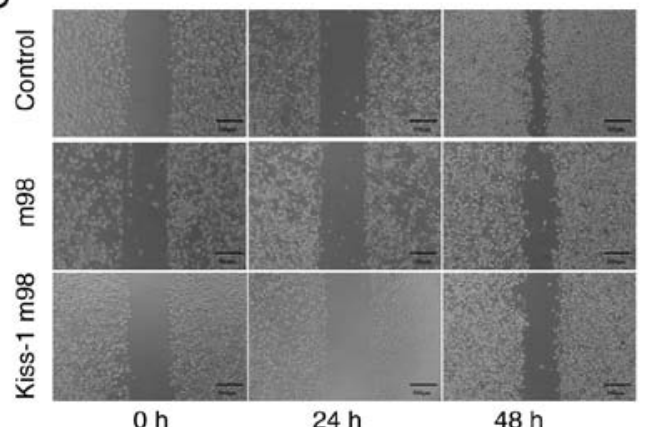

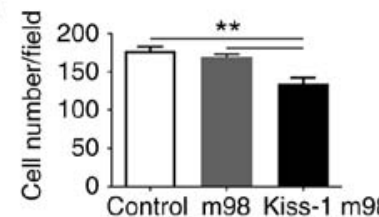
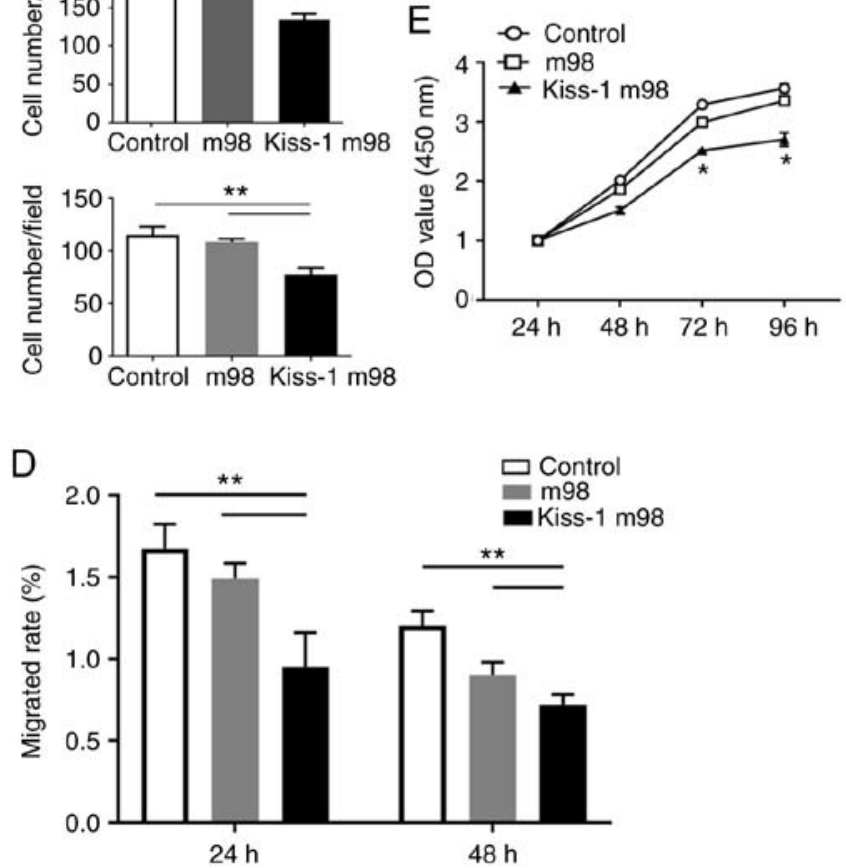

Figure 4. The effect of Kiss-1 overexpression on GC cells was examined. (A) Representative image of Kiss-1 overexpressing cell migration/invasion of the chamber membrane. (B) The mean number of migrated/invaded cells in control, m98 and Kiss-1 m98 groups; ${ }^{* *} \mathrm{P}<0.01$. (C) Representative image of wound healing assay in Kiss-1 overexpression cells. (D) Quantitative analysis of the percentage of wound closure in the control, $\mathrm{m} 98$ and Kiss-1 $\mathrm{m} 98$ groups; ${ }^{* *} \mathrm{P}<0.01$. (E) Effects of Kiss-1 overexpression on cell growth using CCK8 assay; ${ }^{*} \mathrm{P}<0.05$.

the pathological parameters of the GC patients indicated association among lymph node metastasis, TNM III+IV stage and the higher methylation positive rate of the Kiss-1 promoter.
This demonstrated that the complexity of tumor pathogenesis was, not only a reflection of genetic change by mutation or deletion, but also a reflection of epigenetic alterations, such 

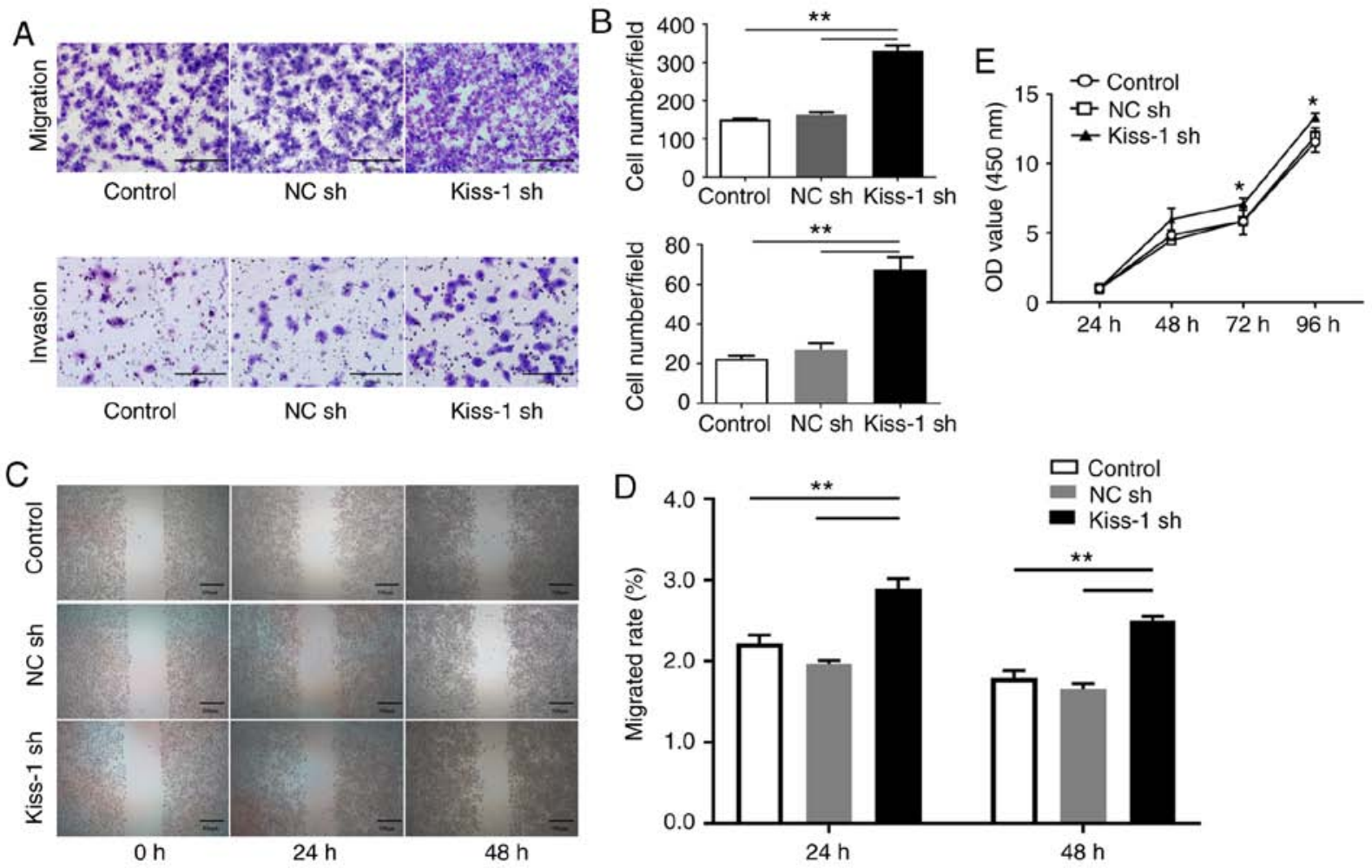

Figure 5. The effect of Kiss-1 knockdown on GC cells was examined. (A) Representative image of Kiss-1 knockdown cell migration/invasion of the chamber membrane. (B) The mean number of migrated/invaded cells in the control, NC sh and Kiss-1 sh groups; ${ }^{* *} \mathrm{P}<0.01$. (C) Representative image of wound healing assay in Kiss-1 knockdown cells. (D) Quantitative analysis of the percentage of wound closure in the control, NC sh and Kiss-1 sh groups; ${ }^{* *} \mathrm{P}<0.01$. (E) Effects of Kiss- 1 knockdown on cell growth using CCK8 assay; ${ }^{*} \mathrm{P}<0.05$.

as DNA methylation. In addition to the deletion and mutation of the associated genes, aberrant changes in DNA methylation were considered as the third mechanism leading to anti-oncogenic inactivation $(19,20)$, which played an essential role in tumor development. A previous study suggested that hypermethylation of Kiss-1 occurred frequently in colorectal cancer (CRC) (21). Moreover, it has been confirmed that Kiss-1 methylation is associated with tumor differentiation, depth of invasion, distant lymph node metastasis and predictive recurrence $(8,21,22)$. These data indicated that Kiss- 1 methylation may be associated with invasion, metastasis and poor prognosis in GC. Results of those studies are similar to those presented in this study.

Kiss- 1 mRNA and protein expression levels are substantially downregulated in GC tissues compared with the corresponding levels noted in non-tumor tissues. This is consistent with the findings of Kostakis et al demonstrating that Kiss- 1 expression in adjacent gastric mucosa was considerably higher than that noted in malignant mucosa (23). Subsequently, we performed statistical analysis of the pathological features of the GC tissues and confirmed that low protein expression levels of Kiss-1 were significantly associated with poor histological grade, lymph node metastasis and TNM III+IV stage. This is consistent with other studies reporting that Kiss- 1 exhibited low expression levels in CRC and that it may be considered a putative metastasis suppressor in human CRC (24-26). It was hypothesized that Kiss-1 promoter methylation resulted in loss of Kiss-1 expression and metastasis of GC. Previous findings have demonstrated that Kiss-1 hypermethylation is associated with loss of transcription and protein expression in CRC (8). Furthermore, promoter $\mathrm{CpG}$ island methylation has been shown to reduce the expression levels of related tumor suppressor genes and is considered the main tumor suppressor-inactivation mechanism in GC (27). Therefore, it was essential to examine whether Kiss-1 expression in GC tissues is also directly affected by the methylation levels of its promoter. Based on results of the present study, we sugget that the Kiss-1 protein plays a role in inhibiting tumor metastasis during the development of GC, further confirming that the Kiss-1 gene is a metastasis suppressor gene in GC and that the downregulation of its expression exhibits considerable significance for clinical development of individualized treatment and disease prognosis.

The biological function of Kiss-1 on AGS and HGC-27 cells was further examined. The data indicated that overexpression of the Kiss- 1 gene significantly inhibited migration and invasion of AGS in the GC cell lines used. Its decreased expression was able to promote migration and invasion of HGC-27 cells. These results are similar to those reported by Lee and Kim demonstrating that Kiss-1 may inhibit the invasion of NUGC-3 and MKN-28 GC cells (28). Chen et al reported that Kiss-1 overexpression significantly decreased the invasiveness of CRC cells (29). Previous reports have also suggested that the reduction of Kiss-1 expression promotes cell migration and invasion in pancreatic (30), ovarian (31), prostate (32) and endometrial cancer (33) as well as in nasopharyngeal carcinoma (34). Considering the importance of migration and invasion as two key processes required for tumor progression and metastasis, the results demonstrated the therapeutic potential of Kiss-1 by reducing tumor cell metastatic activity. 
The data from the proliferation experiments indicated that the overexpression of Kiss-1 exhibited an inhibitory effect in AGS cells, whereas its knockdown exhibited a promoting effect in the proliferation of HGC-27 cells. These effects appeared $48 \mathrm{~h}$ following treatment mainly because Kiss-1 required a longer time to exert its effect on proliferation. Notably, the role of Kiss-1 in the proliferation of various tumors has been well established. Chen et al (29) demonstrated that silencing of the Kiss-1 gene did not influence proliferation of HCT-116 CRC cells, whereas its overexpression resulted in the opposite effects. Knockdown of Kiss-1 in HT115 and HRT18 CRC cells did not have an effect on their proliferation (25). Certain inconsistent proliferation results may be associated with the characteristics of different tumor cells. It has been reported that Kiss- 1 inhibits growth of matrix-independent tumors but not of matrix-dependent tumors (34). Therefore, the regulation of Kiss-1 in different tumor phenotypes is more complex than expected and requires further investigation. Some previous studies have only examined Kiss- 1 expression in GC tissues or part of its biological role in GC cells $(23,28)$. By contrast, our research systematically investigated the role of Kiss-1 in GC, including mRNA expression, protein expression, methylation status, and clinicopathological data in GC tissues, as well as biological functions after upregulation and downregulation of Kiss-1 in GC cells. We hypothesized that Kiss-1 promoter methylation would lead to loss of Kiss-1 expression, thereby promoting the metastasis of GC. This makes our research content more diverse and the results clearer.

In conclusion, the experiments demonstrated that Kiss-1 may be considered a tumor metastasis suppressor gene closely associated with the development of GC. Kiss-1 was able to inhibit migration and invasion of GC to a certain extent. Consequently, Kiss- 1 can be used as a new target for clinical treatment, which may not only eliminate local disease, but also inhibit the systemic spread of GC cells. Additional future studies should be performed to confirm these findings.

\section{Acknowledgements}

We would like to thank Professor Quanhai Li and Dr Xia Jiang for experimental suggestions and writing guidance.

\section{Funding}

This study was supported by the Hebei Province Key Research and Development Project (grant no. 18277741D) and other Hebei Province Projects (grant nos. 1387, SGH201501, A201802017, LNB201809, G2019035, ZD20140126 and XH201805).

\section{Availability of data and materials}

The datasets used and/or analyzed during the current study are available from the corresponding author on reasonable request.

\section{Authors' contributions}

WY designed the study. CL, MX and DL performed the experiments. LY, SH and BT analyzed the data. CL and LY wrote the manuscript together. WY helped to revise the manuscript. All authors read and approved the final manuscript and agree to be accountable for all aspects of the research in ensuring that the accuracy or integrity of any part of the work are appropriately investigated and resolved.

\section{Ethics approval and consent to participate}

The study was approved by the Institutional Ethical Review Committee of the First Hospital of Hebei Medical University and adhered to the principles of the Declaration of Helsinki. Informed consent was obtained from each patient before collection of tissues.

\section{Patient consent for publication}

Not applicable.

\section{Competing interests}

The authors declare that they have no competing interests.

\section{References}

1. Bray F, Ferlay J, Soerjomataram I, Siegel RL, Torre LA and Jemal A: Global cancer statistics 2018: GLOBOCAN estimates of incidence and mortality worldwide for 36 cancers in 185 countries. CA Cancer J Clin 68: 394-424, 2018.

2. Chen W, Sun K, Zheng R, Zeng H, Zhang S, Xia C, Yang Z, Li H, Zou X and He J: Cancer incidence and mortality in China, 2014. Chin J Cancer Res 30: 1-12, 2018.

3. Samant RS, Seraj MJ, Saunders MM, Sakamaki TS, Shevde LA, Harms JF, Leonard TO, Goldberg SF, Budgeon L, Meehan WJ, et al: Analysis of mechanisms underlying BRMS1 suppression of metastasis. Clin Exp Metastasis 18: 683-693, 2000.

4. Lee JH, Miele ME, Hicks DJ, Phillips KK, Trent JJM, Weissman BE and Welch DR: KiSS-1, a novel human malignant melanoma metastasis-suppressor gene. J Natl Cancer Inst 88: 1731-1737, 1996.

5. Clements MK, McDonald TP, Wang R, Xie G, O'Dowd BF, George SR, Austin CP and Liu Q: FMRFamide-related neuropeptides are agonists of the orphan G-protein-coupled receptor GPR54. Biochem Biophys Res Commun 284: 1189-1193, 2001.

6. Stafford LJ, Xia C, Ma W, Cai Y and Liu M: Identification and characterization of mouse metastasis-suppressor KiSS1 and its G-protein-coupled receptor. Cancer Res 62: 5399-5404, 2002.

7. Zhang Y, Huang Z, Zhu Z, Zheng X, Liu J, Han Z, Ma X and Zhang Y: Upregulated UHRF1 promotes bladder cancer cell invasion by epigenetic silencing of KiSS1. PLoS One 9: e104252, 2014.

8. Moya P, Esteban S, Fernandez-Suarez A, Maestro M, Morente M and Sánchez-Carbayo M: KiSS-1 methylation and protein expression patterns contribute to diagnostic and prognostic assessments in tissue specimens for colorectal cancer. Tumour Biol 34: 471-479, 2013.

9. Teng Y, Mei Y, Hawthorn L and Cowell JK: WASF3 regulates miR-200 inactivation by ZEB1 through suppression of KISS1 leading to increased invasiveness in breast cancer cells. Oncogene 33: 203-211, 2014.

10. Yamashita S, Tsujino Y,Moriguchi K, Tatematsu M and Ushijima T: Chemical genomic screening for methylation-silenced genes in gastric cancer cell lines using 5-aza-2'-deoxycytidine treatment and oligonucleotide microarray. Cancer Sci 97: 64-71, 2006.

11. Livak KJ and Schmittgen TD: Analysis of relative gene expression data using real-time quantitative PCR and the 2(-Delta Delta C(T)) method. Methods 25: 402-408, 2001.

12. Wolf K, Wu YI, Liu Y, Geiger J, Tam E, Overall C, Stack MS and Friedl P: Multi-step pericellular proteolysis controls the transition from individual to collective cancer cell invasion. Nat Cell Biol 9: 893-904, 2007.

13. Hou JM, Krebs M, Ward T, Sloane R, Priest L, Hughes A, Clack G, Ranson M, Blackhall F and Dive C: Circulating tumor cells as a window on metastasis biology in lung cancer. Am J Pathol 178: 989-996, 2011. 
14. Kienast Y, von Baumgarten L, Fuhrmann M, Klinkert WEF Goldbrunner R, Herms J and Winkler F: Real-time imaging reveals the single steps of brain metastasis formation. Nat Med 16: 116-122, 2010

15. Lee JH and Welch DR: Suppression of metastasis in human breast carcinoma MDA-MB-435 cells after transfection with the metastasis suppressor gene, KiSS-1. Cancer Res 57: 2384-2387, 1997.

16. Lee JH and Welch DR: Identification of highly expressed genes in metastasis-suppressed chromosome 6/human malignant melanoma hybrid cells using subtractive hybridization and differential display. Int J Cancer 71: 1035-1044, 1997.

17. Kotani M, Detheux M, Vandenbogaerde A, Communi D, Vanderwinden JM, Poul EL, Brézillon S, Tyldesley R, Suarez-Huerta N, Vandeput F, et al: The metastasis suppressor gene KiSS-1 encodes kisspeptins, the natural ligands of the orphan $G$ protein-coupled receptor GPR54. J Biol Chem 276: 34631-34636, 2001.

18. Ohtaki T, Shintani Y, Honda S, Matsumoto H, Hori A Kanehashi K, Terao Y, Kumano S, Takatsu Y, Masuda Y, et al Metastasis suppressor gene KiSS-1 encodes peptide ligand of a G-protein-coupled receptor. Nature 411: 613-617, 2001.

19. Fang JY and Lu YY: Effects of histone acetylation and DNA methylation on p21( WAF1) regulation. World J Gastroenterol 8: 400-405, 2002

20. Kumar R and Xi Y: MicroRNA, epigenetic machinery and lung cancer. Thora Cancer 2: 35-44, 2011.

21. Chen SQ, Chen ZH, Lin SY, Dai QB, Fu LX and Chen RQ: KISS1 methylation and expression as predictors of disease progression in colorectal cancer patients. World J Gastroenterol 20 10071-10081, 2014.

22. Cebrian V, Fierro M, Orenes-Piñero E, Grau L, Moya P, Ecke T, Alvarez M, Gil M, Algaba F, Bellmunt J, et al: KISS1 methylation and expression as tumor stratification biomarkers and clinical outcome prognosticators for bladder cancer patients. Am J Pathol 179: 540-546, 2011.

23. Kostakis ID, Agrogiannis G, Vaiopoulos AG, Mylona E, Patsouris E, Kouraklis G and Koutsilieris M: KISS1 and KISS1R expression in gastric cancer. J BUON 23: 79-84, 2018.

24. Kostakis ID, Agrogiannis G, Vaiopoulos AG, Mylona E, Patsouris E, Kouraklis G and Koutsilieris M: A clinicopathological analysis of KISS1 and KISS1R expression in colorectal cancer. APMIS 123: 629-637, 2015.
25. Ji K, Ye L, Ruge F, Hargest R, Mason MD and Jiang WG: Implication of metastasis suppressor gene, Kiss-1 and its receptor Kiss-1R in colorectal cancer. BMC Cancer 14: 723, 2014.

26. Huo X, Zhang L and Li T: Analysis of the association of the expression of KiSS-1 in colorectal cancer tissues with the pathology and prognosis. Oncol Lett 15: 3056-3060, 2018

27. Guan Z, Zhang J, Song S and Dai D: Promoter methylation and expression of TIMP3 gene in gastric cancer. Diagn Pathol 8: 110, 2013.

28. Lee KH and Kim JR: Kiss-1 suppresses MMP-9 expression by activating p38 MAP kinase in human stomach cancer. Oncol Res 18: 107-116, 2009.

29. Chen S, Chen W, Zhang X, Lin S and Chen Z: Overexpression of KiSS-1 reduces colorectal cancer cell invasion by downregulating MMP-9 via blocking PI3K/Akt/NF- $\mathrm{B}$ signal pathway. Int J Oncol 48: 1391-1398, 2016.

30. Wang CH, Qiao C, Wang RC and Zhou WP: KiSS-1-mediated suppression of the invasive ability of human pancreatic carcinoma cells is not dependent on the level of KiSS-1 receptor GPR54. Mol Med Rep 13: 123-129, 2016.

31. Jiang Y, Berk M, Singh LS, Tan H, Yin L, Powell CT and Xu Y: KiSS1 suppresses metastasis in human ovarian cancer via inhibition of protein kinase $\mathrm{C}$ alpha. Clin Exp Metastasis 22: 369-376, 2005.

32. Wang H, Jones J, Turner T, He QP, Hardy S, Grizzle WE, Welch DR and Yates C: Clinical and biological significance of KISS1 expression in prostate cancer. Am J Pathol 180: 1170-1178, 2012.

33. Kang HS, Baba T, Mandai M, Matsumura N, Hamanishi J, Kharma B, Kondoh E, Yoshioka Y, Oishi S, Fujii N, et al: GPR54 is a target for suppression of metastasis in endometrial cancer. Mol Cancer Ther 10: 580-590, 2011.

34. Wang GM, Liu JF, Zhang L, Sun Q, Zhou Y, Xu HB, Zhang YJ, Cai F, Cheng ZN, Xiang P and Jiang H: Inhibition of KiSS-1 on metastasis of nasopharyngeal carcinoma implant tumor in nude mice. Am J Transl Res 11: 904-910, 2019.

(i) 1 This work is licensed under a Creative Commons Attribution-NonCommercial-NoDerivatives 4.0 International (CC BY-NC-ND 4.0) License. 